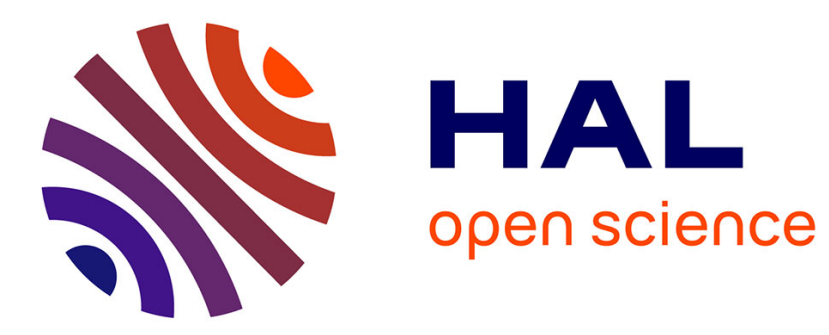

\title{
Risk assessment of Belgian adults for furan contamination through the food chain
}

Georges Scholl, Marie-France Humblet, Marie-Louise Scippo, Edwin de Pauw, Gauthier Eppe, Claude Saegerman

\section{- To cite this version:}

Georges Scholl, Marie-France Humblet, Marie-Louise Scippo, Edwin de Pauw, Gauthier Eppe, et al.. Risk assessment of Belgian adults for furan contamination through the food chain. Food Additives and Contaminants, 2011, pp.1. 10.1080/19440049.2011.637240 . hal-00765016

\section{HAL Id: hal-00765016 https://hal.science/hal-00765016}

Submitted on 14 Dec 2012

HAL is a multi-disciplinary open access archive for the deposit and dissemination of scientific research documents, whether they are published or not. The documents may come from teaching and research institutions in France or abroad, or from public or private research centers.
L'archive ouverte pluridisciplinaire HAL, est destinée au dépôt et à la diffusion de documents scientifiques de niveau recherche, publiés ou non, émanant des établissements d'enseignement et de recherche français ou étrangers, des laboratoires publics ou privés. 


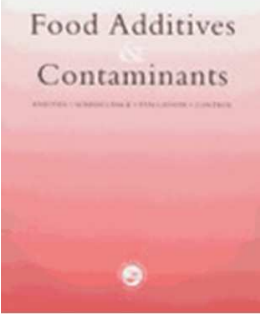

\section{Risk assessment of Belgian adults for furan contamination through the food chain}

\begin{tabular}{|c|c|}
\hline Journal: & Food Additives and Contaminants \\
\hline Manuscript ID: & TFAC-2011-288.R1 \\
\hline Manuscript Type: & Original Research Paper \\
\hline Date Submitted by the Author: & 27-Oct-2011 \\
\hline Complete List of Authors: & $\begin{array}{l}\text { Scholl, Georges; Liege University, Chemistry } \\
\text { Humblet, Marie-France; University of Liege, Infectious and Parasitic } \\
\text { Diseases } \\
\text { Scippo, Marie-Louise; University of Liege, Food Science } \\
\text { de pauw, edwin; Liege University, Chemistry } \\
\text { Eppe, Gauthier; University of Liege, CART } \\
\text { Saegerman, Claude; University of Liege, Faculty of Veterinary Medecine, } \\
\text { Department of Infectious and Parasitic Diseases, Epidemiology and Risk } \\
\text { analysis applied to Veterinary sciences }\end{array}$ \\
\hline Methods/Techniques: & Risk assessment, GC, Extraction, Exposure assessment \\
\hline Additives/Contaminants: & Process contaminants \\
\hline Food Types: & Animal products - meat, Bakery products, Canned foods, Cereals \\
\hline Abstract: & $\begin{array}{l}\text { Risk assessment is an interdisciplinary process used to quantify the risk } \\
\text { linked to a hazard. In the present paper, it is applied to quantify the risk } \\
\text { linked to furan ingestion through the food chain for the Belgian adult } \\
\text { population. Two approaches, deterministic and probabilistic, are carried out } \\
\text { in parallel. The deterministic method relies on a case-study, whereas the } \\
\text { probabilistic approach involves statistical distributions of contamination and } \\
\text { consumption data to calculate a statistical distribution of the daily intake. } \\
\text { First, the deterministic method revealed a low Estimated Daily Intake (EDI) } \\
\text { for the average population ( } 380 \mathrm{ng} * \text { (kgb.w.*day)-1) and a huge } \\
\text { contribution of coffee consumption to the EDI ( } 55 \% \text { ). Increasing or } \\
\text { decreasing by one cup the daily coffee consumption can affect the EDI by } \\
\text { about } 22 \% \text {. Afterwards, the probabilistic approach showed that the } \\
\text { average population has a low EDI ( } 494 \text { ng * (kgb.w.*day)-1), and that } \\
\text { high contamination levels were only registered in a small proportion of the } \\
\text { population. Finally, a comparison to the RfDchronic-oral showed that less } \\
\text { than } 10 \% \text { of the Belgian population presents an EDI above the reference } \\
\text { dose proposed by the US-EPA; the majority of the population presents an }\end{array}$ \\
\hline
\end{tabular}


2

3

4

5

6

7

8

9

10

EDI $20 \%$ below the reference dose. The Margin of Exposure (MoE) approach revealed that the level of risk related to furan intake through ingestion is low, with a MoE above 10,000 for more than $10 \%$ of the population and no result below 100 .

\section{SCHOLARONE ${ }^{m}$}

Manuscripts 


\section{Risk assessment of Belgian adults for furan contamination through the food}

\section{2 chain}

3

4 Georges Scholl ${ }^{1 \& 2}$, Marie-France Humblet ${ }^{1}$, Marie-Louise Scippo ${ }^{3}$, Edwin De Pauw ${ }^{2}$, 5 Gauthier Eppe ${ }^{4}$ and Claude Saegerman ${ }^{1}$

6

$7{ }^{1}$ Research Unit in Epidemiology and Risk Analysis applied to veterinary sciences (UREAR),

8 Department of Infectious and Parasitic Diseases, Faculty of Veterinary Medicine, University

9 of Liege, Boulevard de Colonster 20, B-42 Sart-Tilman, B-4000 Liege, Belgium

$11{ }^{2}$ CART, Mass Spectrometry Laboratory, Chemistry Department, University of Liege, Allée de 12 la Chimie 3, B-6c Sart-Tilman, B-4000 Liege, Belgium

${ }^{3}$ CART, Laboratory of Food Analysis, Faculty of Veterinary medicine, University of Liege, 15 Boulevard de Colonster 20, B-43bis Sart-Tilman, B-4000 Liege, Belgium

${ }^{4}$ CART, Inorganic Analytical Chemistry, Chemistry Department, University of Liege, Allée de 18 la Chimie 3, B-6c Sart-Tilman, B-4000 Liege, Belgium

20 Correspondence: Claude Saegerman, Research Unit of Epidemiology and Risk Analysis 21 applied to veterinary sciences (UREAR), Department of Infectious and Parasitic Diseases, 22 Faculty of Veterinary Medicine, University of Liege, Boulevard de Colonster, 20, B42, B234000 Liege, Belgium

24 Email: claude.saegerman@ulg.ac.be 


\section{Abstract}

27 Risk assessment is an interdisciplinary process used to quantify the risk linked to a hazard. In the present paper, it is applied to quantify the risk linked to furan ingestion through the food chain for the Belgian adult population. Two approaches, deterministic and probabilistic, were carried out in parallel. The deterministic method relied on a case-study, whereas the probabilistic approach involved statistical distributions of contamination and consumption data to calculate a statistical distribution of the daily intake. First, the deterministic method revealed a low Estimated Daily Intake (EDI) for the average population (380 ng * $\left.\left(\mathrm{kg}_{\mathrm{b.w}} * \text { day }\right)^{-1}\right)$ and a huge contribution of coffee consumption to the EDI (55\%). Increasing or decreasing by one cup the daily coffee consumption can affect the EDI by about $22 \%$. Afterwards, the probabilistic approach showed that the average population has a low EDI $\left(494 \mathrm{ng} *\left(\mathrm{~kg}_{\text {b.w. }} * \text { day }\right)^{-1}\right)$, and that high contamination levels were only registered in a small proportion of the population. Finally, a comparison to the $\mathrm{RfD}_{\text {chronic-oral }}$ showed that less than $10 \%$ of the Belgian population had an EDI above the reference dose proposed by the USEPA; the majority of the population had an EDI $20 \%$ below the reference dose. The Margin of Exposure (MoE) approach indicated that the level of risk related to furan intake through ingestion is low, with a MoE above 10,000 for more than $10 \%$ of the population and no result below 100 .

Keywords: Furan, Adult, Risk assessment, Food Chain, Belgium

46

\section{Introduction}

Risk assessment is: 'The estimation of the nature and probability of adverse health effects related to a hazard, e.g., microbiology, chemistry, fire, riots, etc. (US-EPA risk assessment ${ }^{1}$;

\footnotetext{
${ }^{1}$ http://epa.gov/riskassessment/index.htm
} 
49 Renwick et al., 2004; Feinberg et al., 2006). In the present paper, the risk related to furan

50 ingestion throughout the food chain is discussed for the Belgian adult population.

51 Furan is a low molecular mass toxicant mainly found in food undergoing heat 52 treatment such as canned, jarred or roasted food (Hasnip et al., 2006; Crews et al., 2007; 53 Roberts et al., 2008; Fromberg et al., 2009; Kim et al., 2009). Maga first reported its 54 occurrence in food in the late 70s (Maga, 1979), but its toxicity was only studied since the 90s 55 (Kedderis et al., 1993; Chen et al., 1995; Peterson et al., 2006; Bakhiya et al. 2010). 56 Consecutively, the American National Toxicology Program (NTP) published a report on its 57 toxicity (NTP, 1993), the American National Academy of Science (NAS) classified it as a 58 narcotic (NAS, 2000), and the International Agency for Research on Cancer (IARC) involved 59 it as possibly carcinogenic to humans (group 2B). Nevertheless, furan has only gained interest 60 since 2004, when the United State Food and Drug Administration published a report about its 61 wide occurrence in food (US-FDA, 2004). Since then, national and international food control 62 authorities started gathering information on furan levels, toxicity and risk for the population 63 (Hepner et al., 2007; Stadler, 2007).

64 Several contamination assessments have been carried out to date, which led to the 65 implementation of food control plans in some countries (Reinhard et al., 2004; Kim et al., 66 2009; Liu and Tsai, 2010). The main contamination assessment was recently achieved for the 67 European population by the European Food and Safety Authorities (EFSA, 2009). It was 68 based on a set of contamination data collected from European control plans, and on several 69 independent contamination studies. EFSA combined these contamination data with the results 70 of consumption surveys from several Europeans countries to estimate the furan daily intake. 71 Nevertheless, the risk linked to furan firstly depends on food consumption habits, and 72 secondly on food contamination levels (Feinberg et al., 2006). As consumption habits are 73 related to subpopulations and locations, the present paper describes a risk assessment 
74 targeting the Belgian adult population. The Estimated Daily Intake (EDI) was calculated 75 using the deterministic and probabilistic methodologies. Afterwards, the risk was estimated 76 both by comparing it to a toxicological reference dose (classical way) and also by calculating 77 the Margin of Exposure (MoE).

\section{Materials and methods}

\section{Contamination data}

80 The contamination dataset only included products sold in Belgium, which were analysed by a 81 previously described methodology (Scholl et al., 2009). This assessment was performed using 82496 items sampled in the whole country (Scholl et al., 2011). Samples were taken all along 83 the food chain, in several food markets. The sampling plan included weighting factors, such 84 as food consumption and already reported contamination levels, to focus on the main food 85 groups. This methodology was also applied to avoid the bias resulting from a similar product 86 sold in several countries, but for which the preparation and/or composition can be different 87 (Wegener and Lopez-Sanchez, 2010).

88 The assessment relied on a sole methodology to avoid the bias resulting from applying 89 several approaches with different detection capabilities $\left(\mathrm{CC}_{\beta}\right)$ (in a first approach equivalent 90 to the limit of quantification (LOQ)), repeatability, precisions, and expanded uncertainties 91 (Scholl et al., 2009). The procedure used is a solid phase micro-extraction (SPME) coupled to 92 a gas chromatography separation followed by a mass spectrometry detection using the 93 isotopic dilution technique for quantification. The analytical approach is very sensitive and 94 provides a response rate of up to $78.2 \%$ above the LOQ.

\section{Consumption data}

96 The Belgian Institute of Public Health provided consumption data. In 2004, De Vriese and co-

97 workers carried out a consumption assessment of the Belgian population (De Vriese et al., 
98 2005). This assessment involved 3,200 people of at least 15 years old from the whole country.

99 The protocol was a recall performed on two non-consecutive days combined to a self-

100 administrated questionnaire on food consumption frequency and a final face-to-face

101 interview. This assessment focused not only on consumption habits, but also on socio-

102 economic data of each participant, providing relevant information to study some

103 subpopulations.

104 Methodology of risk assessment

105 Hazard Identification

106 Furan is a toxic present in the food chain. In 1993, the NTP published a first report on furan

107 toxicity and carcinogenicity based on in vivo studies on rat. This report was used in 1995 by

108 the International Agency for Research on Cancer (IARC) to classify it in the group 2B, which

109 means 'possibly carcinogenic to humans'. Five years later, the NAS also classified it as a

110 narcotic. Several independent toxicological studies highlighting the carcinogenic effect of its

111 metabolites have been performed since the 90s, (Kedderis et al., 1993; Chen et al., 1995;

112 Peterson et al., 2000; Peterson et al., 2005; Peterson et al., 2006; Bakhiya et al. 2010;

113 Hamberger et al., 2010). More recent studies revealed that furan toxicity was linked to its

114 major primary metabolite, the cis-2-butene-1,4-dial, able to induce tumours through a

115 genotoxic effect on liver cells (Chen et al., 1995; Peterson et al., 2000; Peterson et al., 2005;

116 Peterson et al., 2006). This metabolite results from the first hepatic transformation of furan by

117 cytochrome P-450. To date, toxicity for humans has only been extrapolated from in vitro and 118 animals studies.

\section{Hazard characterisation}

120 Hazard characterisation corresponds to a dose-response assessment. It is a toxicological step

121 describing the mechanism of action including dynamic and kinetic aspects. The main intake 
122 pathway of furan into the body is the food chain. The low polarity of furan allows it to easily

123 cross biological membranes. Studies on rats revealed that about $80 \%$ of furan is eliminated 124 within 24 hours: $40 \%$ by respiration, $22 \%$ in faeces and $20 \%$ in urine (Burka et al., 1991).

125 The remaining $18 \%$ are rapidly metabolised by hepatic enzymes of the cytochrome P-450 into 126 more than 10 metabolites (Bakhiya et al., 2010). Its major primary metabolite, the cis-2127 butene-1,4-dial resulting from furan oxidation, is known to induce hepatocellular tumour and 128 mononuclear cell leukaemia in rats. Furan is also known to induce cholangiocarcinomas in rat 129 liver through an oxidative stress mechanism (Hickling et al., 2010a,b)

130 In the late 80s, the US-EPA proposed a Reference Dose for Chronic Oral Exposure 131 (RfD) based on NTP studies (US-EPA Integrated Risk Information System²). This dose was 132 calculated according to a 13 week-study involving rat gavages aiming at inducing hepatic 133 lesions. The Lowest Observed Adverse Effect Level (LOAEL) was then estimated to be 4 $134 \mathrm{mg} *\left(\mathrm{~kg}_{\text {body }} \text { weight and day }\right)^{-1}$ for rats. The No Observed Adverse Effect Level (NOAEL) was 135 fixed at $2 \mathrm{mg} *\left(\mathrm{~kg}_{\text {b.w. }} * \text { day }\right)^{-1}$. The application of several precaution factors allowed the US136 EPA to recommend a $\operatorname{RfD}_{\text {chronic-oral }}$ of $1 \mu \mathrm{g} *\left(\mathrm{~kg}_{\text {b.w. }} * \text { day }\right)^{-1}$ for humans.

137 In addition, based on the NTP and on the Moser and co-workers studies (Moser et al., 138 2009), a benchmark dose for $10 \%$ extra risk $\left(\mathrm{BMD}_{10}\right)$ of hepatocellular adenomas and 139 carcinoma was established. Subsequently, a 95\% lower confidence limit for this benchmark 140 dose $\left(\mathrm{BMDL}_{10}\right)$ for the same Mode of Action $(\mathrm{MoA})$ was reported to be $0.96 \mathrm{mg}$ * $141 \quad$ (kg.w. $\left._{\text {bday }}\right)^{-1}$ (Benford et al., 2010; Carthew et al., 2010; Williams et al, 2011).

\section{Exposure Assessment}

143 The exposure assessment aims at estimating the daily intake of a toxic (EDI). When available, 144 the EDI may be combined to the daily out-take to estimate the mean absorption.

\footnotetext{
${ }^{2}$ http://www.epa.gov/iris/subst/0056.htm
} 
145 Furan daily intake throughout the food chain is calculated by applying three equations,

146 namely Equation 1, Equation 2 and Equation 3. The first equation means the global EDI

147 equals the sum of individual EDIs (EDI of each food group). The second equation explains

148 that a food group EDI results from multiplying the specific food group relative consumption

149 by the food group contamination. The third equation shows that the relative daily

150 consumption corresponds to the ratio between the daily consumption and the 'population'

151 weight.

152 Equation 1: Calculation of global EDI

$$
E D I_{\text {Global }}=\sum_{\text {FoodGroup }} E D I_{\text {FoodGroup }}
$$

154 Equation 2: calculation of EDI

156 Equation 3: Estimation of the relative daily consumption relativeDailyConsumption $=\frac{\text { DailyConsumption }}{\text { Weight }}$

Two approaches were applied to calculate the EDI: deterministic and probabilistic; both methods are described in the following sections.

161 In the deterministic approach, the EDI was calculated for several categories of the population

162 according to selected cases, e.g. mean or worst case. As furan contamination is directly 163 related to food origin and preparation (Crews and Castle, 2007; Wegener and López-Sánchez, 164 2010), only the results of the previously mentioned Belgian contamination assessment were 165 used (Scholl et al., 2011). Three different approaches are recommended by the WHO to deal 166 with contamination data below the quantification limits (WHO, 2003). These approaches are 167 named Lower Bound (LB), Middle Bound (MB) and Upper Bound (UB), where results below 
168 the limit of quantification (LOQ) are respectively replaced by 0 , half-LOQ and LOQ itself. In

169 the present study, as the proportion of non-quantifiable results was very low $(<12 \%)$, these

170 approaches were expected to provide quite similar results. Consumption depends on the 171 population studied; therefore, only data from the 'First Belgian consumption survey' (De

172 Vriese et al., 2005) were used. Several categories of population were studied for each food 173 group such as the average consumption, the $2.5^{\text {th }}, 25^{\text {th }}, 50^{\text {th }}, 75^{\text {th }}$, and $97.5^{\text {th }}$ consumption 174 percentiles. These categories of population are assessable by two ways depending on how 175 unconsummated items are dealt with. On one hand, the statistical analysis is performed by 176 considering only the subpopulation consuming the food group; statistical results of 177 consumption are therefore not representative of the whole population. On the other hand, the 178 whole population is included, and the no-consumption of a food item is characterised by a 179 null-consumption value. The first approach is usually applied in cases of acute toxicity as is 180 more related to a punctual dose, which is the most appropriate for a worst case-study. The 181 second approach is generally applied in case of chronic toxicity as it considers the possibility 182 of not consuming a food item. As furan is known to have a chronic toxicity, only the second 183 procedure was applied in the present paper.

184 The real weight of each participant to the food consumption survey was used to 185 estimate the EDI more accurately as it was available.

\section{Probabilistic approach}

187 In this approach, raw (consumption and contamination) data are converted into a function of 188 occurrence (Table I) and computed using the @Risk software (version 5.5; Palisade 189 Corporation, New York, USA). Afterwards, functions are combined through Eq.1, Eq.2 and 190 Eq.3 by using a Monte-Carlo simulation with 500,000 iterations to obtain a function of furan 191 EDI. 
192 Functions of contamination occurrence are computed in two steps. The function of

193 each food group is first determined by only including contamination data >LOQ (this function

194 is truncated such as no result <LOQ can be drawn). Thereafter, a function dealing with the 195 probability to have a data <LOQ is added to the occurrence function determined in the first 196 step. The nature of the second function depends on the approach used to deal with data $197<$ LOQ. In the probabilistic method, the three approaches described in the deterministic section 198 (LB, MB and UB) were also applied. A fourth approach named Uniform and involving a 199 random distribution of data <LOQ, was used as well, because it appears more representative 200 of the reality. Practically, in the first three approaches, a discrete function corresponding to, 201 respectively, 0, LOQ/2 and LOQ was used, while a uniform distribution between 0 and LOQ 202 was applied in the fourth approach. Four bimodal functions corresponding to the four 203 approaches were calculated for each food group.

204 The functions of consumption occurrence were also computed in two steps based on 205 raw data of the Belgian consumption survey. First of all, a function was computed for each 206 food group by including only the consuming subpopulation (functions are also truncated to 207 avoid $\mathrm{a} \leq 0$ consumption draw). Secondly, the subpopulation not consuming the food item 208 was calculated. A discrete function set to 0 was then proportionally added to the function 209 calculated in the first step. Therefore, the resulting function of consumption occurrence 210 resulting is bimodal like the contamination function.

211 In this approach, the real population weight was also used and represented by a 212 statistical distribution of the population weight reported in the consumption survey.

\section{Risk characterisation}

214 Two risk characterisation approaches are presented in this paper: a classical way and a new 215 method. In the first one, conclusions have been drawn from comparing the EDIs of several 216 proportions of the population to toxicological reference doses. However, as carcinogenic 
217 effects have no threshold values, a new methodology called Margin of Exposure (MoE) was

218 recently developed (ILSI, 2009). In the MoE approach, a level of concern for the risk linked

219 to a Mode of Action (MoA) is calculated (Eq.4).

220 Equation 4: MoE calculation for a carcinogenic MoA

$$
M o E=\frac{B M D L_{10}}{E D I}
$$

221 Where $\mathrm{DMDL}_{10}$ is the $95 \%$ lower confidence limit for this benchmark dose for $10 \%$ extra risk 222 of hepatocellular adenomas and carcinoma and EDI is the estimated daily intake.

223 The risk may be considered as negligible if the MoE is $>10,000$. On the other hand, a $224 \mathrm{MoE}<100$ is of major concern. Finally, discussions are needed, according to the involved 225 MoA, for a MoE included in a range between 10,000 and 100 (ILSI, 2009).

226 Results

227 Deterministic approach

228 Results of the deterministic risk assessments are summarised in Table II and Figure 1. The 229 three approaches used to deal with values <LOQs gave quite similar results, as shown in 230 Table II. There is a $<2 \mathrm{ng} *\left(\mathrm{~kg}_{\text {b.w. }} * \text { day }\right)^{-1}$ difference between LB and UB for the average 231 population; it is a consequence of the high proportion of results $>$ LOQs $(>78 \%)$ in the 232 contamination assessment. In Figure 1, only the MB approach was illustrated for a question of 233 readability.

234 Average and median population EDIs are close (respectively 380 and $330 \mathrm{ng} *$ $\left.235\left(\mathrm{~kg}_{\text {b.w. }} * \text { day }\right)^{-1}\right)$. Therefore, the distribution of the 3,200 individual EDIs across the population 236 tends to normality, as illustrated in Figure 2A. The figure also shows that the majority of the 237 population has a low EDI with a mode at $225 \mathrm{ng} *\left(\mathrm{~kg}_{\mathrm{b} . w .} * \text { day }\right)^{-1}$ for $9.5 \%$ of the studied 238 population. In this approach, the minimal and maximal EDIs were 0.7 and 3,843 ng * 239 $\left(\mathrm{kg}_{\text {b.w. }} * \text { day }\right)^{-1}$, respectively. 
Only $2.7 \%$ of the population presented an EDI above the $\mathrm{RfD}_{\text {chronic-oral }}$. The majority of

241 the population has an EDI equivalent to $22 \%$ of the $\mathrm{RfD}_{\text {chronic-oral, }}$, and the average population

242 EDI is equivalent to $38 \%$ of the $\mathrm{RfD}_{\text {chronic-oral }}$.

243 Figure 2A also displays the MoE calculation while the proportion of the population at

244 a given MoE is presented in Figure 2C. About $10 \%$ of the population presents a MoE $>10,000$

245 and a MoE $>1,500$ is observed for $>90 \%$ of the population. The minimal calculated MoE was

246404 for $0.02 \%$ of the population and no MoE was <100. Finally, the MoE dispersion mode is

2474,266 for $9.5 \%$ of the population. The main contributors to the EDI are shown in Figure 1.

248 Coffee contributes by $55 \%$ to the average EDI, and the other main groups are: soups, prepared

249 meat, pasta and rice and potatoes with an overall contribution of $26 \%$ to the EDI (ranging

250 individually from 4 to $9 \%$ ).

\section{Coffee consumption scenario}

252 Coffee was shown to be the major contributor (55\%) to the average EDI. This average EDI

253 was achieved after a daily consumption of three cups. The influence of reducing or increasing

254 by one cup the daily consumption was tested in the proposed scenario, as shown in Figure 3.

255 These variations induced a $21 \%$ increase $\left(460 \mathrm{ng} *\left(\mathrm{~kg}_{\mathrm{b} . w .} * \text { day }\right)^{-1}\right)$ and a $23 \%$ decrease $(294 \mathrm{ng}$

$\left.256 *\left(\mathrm{~kg}_{\text {b.w. }} * \text { day }\right)^{-1}\right)$ of the average EDI $\left(380 \mathrm{ng} *\left(\mathrm{~kg}_{\mathrm{b} . \mathrm{w} .} * \text { day }\right)^{-1}\right)$, corresponding to a $12 \%$

257 reduction (or $8 \%$ increase) of the contribution to the EDI when simulating both scenarios.

\section{Probabilistic approach}

259 Results of the probabilistic risk assessment are summarized in Table III and Figure 2B. Figure

260 2B displays the distribution of EDIs across the population. A uniform distribution for the

261 results <LOQ and a statistical distribution of the body weights were used to estimate the 262 EDIs. 
263 Differences between the contamination approaches are shown in Table III. A 264 difference of $6 \mathrm{ng} *\left(\mathrm{~kg}_{\text {b.w. }} * \text { day }\right)^{-1}$ (from 488 to 494$)$ was highlighted for the average 265 population. Consequently, it was decided to show only the results of the uniform distribution 266 approach in the figures. The median EDI represents $43 \%\left(212 \mathrm{ng} *\left(\mathrm{~kg}_{\text {b.w. }}{ }^{*} \text { day }\right)^{1}\right)$ of the 267 average EDI and is not a normal distribution as confirmed by Figure 2B. The EDI of the 268 majority of the population is low $\left(23 \mathrm{ng} *\left(\mathrm{~kg}_{\mathrm{b} . \mathrm{w}} * \text { day }\right)^{-1}\right)$, corresponding to $5 \%$ of the average 269 EDI.

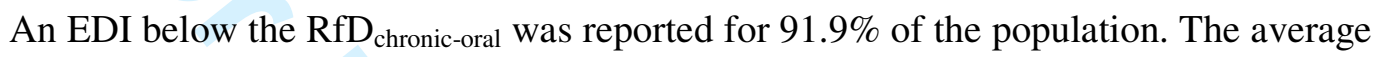
271 EDI and the EDI of the majority of the population represented, about $49 \%$ and $0.2 \%$ of the 272 RfD $_{\text {chronic-oral, }}$ respectively.

273 MoEs related to specific EDIs are displayed in Figure 2B, while the proportion of the 274 population relative to a MoE are shown in Figure 2D. A MoE above 10,000 was reported for $27530 \%$ of the population. Seventeen percent of the population presented a MoE of 38,400 276 (distribution mode) and $90 \%$ of the population had a MoE above 1,164. Calculated MoE 277 decreased until 0.1 for a maximum estimated EDI of $9.2 \mathrm{mg} *(\mathrm{kgb} . \mathrm{w} . *$ day $)-1(<0.0002 \%$ of 278 the population), while only $0.03 \%$ of the population displayed a $\mathrm{MoE}<380$.

\section{Discussion}

\section{Consumption data}

281 As previously mentioned, it was decided to use Belgian datasets with the objective to avoid 282 bias linked to consumption habits observed in other countries. Several consumption surveys 283 have been carried out to date in Belgium, but only the Belgian study achieved in 2004 284 included the whole adult population. This survey was representative of the Belgian population 285 as it included 3,200 people (out of a 10,400,000-global population registered in 2004), from 286 the whole country, and homogeneously distributed according to gender, age, education level, 
287 working field, etc. Nevertheless, data are out-dated as the survey was performed 7 years ago.

288 However, consumption habits have probably not evolved a lot since the end of the survey.

289 Thus, one can assume that differences between current and reported consumption habits are

290 minor. The ideal situation would have been to work on a freshly updated survey involving a

291 constant review of data, but such a tool is not yet available.

\section{Contamination data}

293 The contamination dataset was provided by a survey focusing on local products in order to 294 avoid any bias linked to different preparations and compositions of the same product sold in 295 other countries. In addition, the study relied on a highly sensitive analytical methodology 296 specifically designed to reach low quantification limits. There are two beneficial 297 consequences. Firstly, a high proportion of data >LOQ (up to 78\%), characterised by small 298 differences between LB and UB, were observed. Secondly, inter-laboratory analytical biases 299 resulting from applying different methodologies (different LOQs, expanded uncertainties, 300 etc.) were eliminated.

301 The representativeness of this study comes from its design. It was constructed to avoid 302 a geographical or branding side effect. The dataset is not out-dated as it was compiled only 303 two years ago. But as already mentioned for the consumption study, regular updates are 304 needed to avoid biases related to a modified production and/or distribution scheme. An on305 going survey based on a constant re-evaluation through a food control plan would be suitable.

\section{Deterministic vs. probabilistic approach}

307 Deterministic and probabilistic approaches should not be seen as different but rather as 308 complementary methods.

309 The comparison of average EDIs only displayed few differences. However, comparing 310 EDI distributions and medians or modes displayed important differences, especially for the 
311 low daily intake. Furthermore, the EDI distribution is narrower and the EDI increases faster in

312 the probabilistic approach compared to the deterministic approach. This is a consequence of a

313 difference of contamination data management. In the deterministic approach, only the average

314 contamination value of each food group was taken into account, whereas in the probabilistic

315 approach, a distribution of values (including 0 and very high levels) was used. Therefore,

316 average EDIs and extreme values are biased, in the deterministic and in the probabilistic

317 approaches respectively.

318 MoE distributions are very different, but led to similar conclusions. The majority of

319 the population presented a high $\mathrm{MoE}$ and a $>10,000 \mathrm{MoE}$ was reported for a meaningful

320 percentage of people. Differences were however observed for extreme values: the minimal

321 MoE was 404 in the deterministic approach, while it decreased to 0.1 in the probabilistic

322 method. Such a low MoE value results from very high consumption and contamination

323 values, only encountered in a statistical distribution. Therefore, such a combination is very

324 unlikely and should be ignored.

325 The same differences were observed in the $\mathrm{RfD}_{\text {chronic-oral }}$ approach: the EDI of the 326 majority of the population corresponded to $<50 \%$ of the $\mathrm{RfD}_{\text {chronic-oral }}$ and few percents had an

327 EDI $>\mathrm{RfD}_{\text {chronic-oral }}$. The probabilistic methodology tended to display a higher risk than the 328 deterministic approach. As already observed for the MoE, it finds its explanation in the 329 unlikely extreme EDI values and biased average values in the probabilistic and in the 330 deterministic approaches respectively. Consequently, most results tended to display a low risk 331 level for furan intake. The real situation should fit between both approaches.

\section{Coffee consumption scenario}

333 Coffee consumption was shown to be a critical parameter regarding its impact on furan daily 334 intake. Several straightforward or basic recommendations such as a reduction of the daily 
335 consumption, a thorough mixing of coffee before drinking or even a coffee percolation allows

336 reducing the exposure (Kuballa et al., 2007).

\section{Conclusion}

338 The present study showed that the majority of the population presents a low daily intake; only 339 extreme consumers are really at risk. The major contamination is due to coffee consumption 340 (one of the most contaminated items) and changing consumption habits can strongly impact 341 the EDI.

342 One must be cautious regarding the conclusions drawn from the risk characterisation.

343 If it is commonly accepted that a $\mathrm{MoE}>10,000$ corresponds to a low risk level, and that a

$344 \mathrm{MoE}<100$ means a high risk, there is no consensus for the results included between 10,000 345 and 100 . In the present survey, 10 to $30 \%$ of the population are exposed to a low risk level. 346 Nevertheless, the risk level is not defined for the remaining 70 to $90 \%$. The majority of the 347 population displays a high MoE and therefore a low risk for the selected MoA (hepatocellular 348 adenomas and carcinomas). Similar conclusions drawn when using the classical way 349 (comparison between EDI and the $\mathrm{RfD}_{\text {chronic-oral }}$ ).

350 Finally, the present study only focused on the adult Belgian population, and a question 351 remains pending about furan exposure of subpopulations at risk, like babies and children. 352 Carrying out a risk assessment targeting these subpopulations would be relevant but remains a 353 great challenge, as few data are available on their consumption habits.

\section{Acknowledgments}

355 This study was funded by the Belgian Federal Public Service of Health, Food Chain Safety 356 and Environment (contract RT 06/01 FURA). The authors wish to thank the Belgian Federal 357 Agency for the Safety of the Food Chain (FASFC) for providing consumption data used in 358 this study. 


\section{References}

360

361

362

363

364

365

366

367

368

369

370

371

372

373

374

375

376

377

378

379

380

381

382

383

384

385

386

387

388

389

390

391

392

Bakhiya, N., \& Appel, K. E. 2010. Toxicity and carcinogenicity of furan in human diet. Archives of Toxicology, 84(7), 563-578.

Benford, D., Bolger, P.M., Carthew, P., Coulet, M., DiNovi, M., Leblanc, J.-C., Renwick, A.G., Setzer, W., Schlatter, J., Smith, B., Slob, W., Williams, G., Wildemann, T. 2010. Application of the Margin of Exposure (MoE) approach to substances in food that are genotoxic and carcinogenic. Food and Chemical Toxicology, 48(S), 2-24.

Burka, L. T., Washburn, K. D., \& Irwin, R. D. 1991. Disposition of $\left[{ }^{14} \mathrm{C}\right]$ furan in the male F344 rat. Journal of Toxicology and Environmental Health, 34(2), 245-257.

Carthew, P., DiNovi, M., Setzer, R.W. 2010. Application of the margin of exposure (MoE) approach to substances in food that are genotoxic and carcinogenic - Example: Furan (CAS No. 110-00-9). Food and Chemical Toxicology, 48(S), 69-74.

Chen, L. J., Hecht, S. S., \& Peterson, L. A. 1995. Identification of cis-2-butene-1,4-dial as a microsomal metabolite of furan. Chemical Research in Toxicology, 8(7), 903-906.

Constable, A., Barlow, S. 2009. Summary report of a workshop held in October 2008. Application of the margin of exposure approach to compounds in food which are both genotoxic and carcinogenic. ILSI Europe Report Series. Available at the URL address: http://www.ilsi.org/Publications/MOE\%20WS\%20Report.pdf.

Crews, C., \& Castle, L. 2007. A review of the occurrence, formation and analysis of furan in heat-processed foods. Trends in Food Science \& Technology, 18, 365-372.

De Vriese, S., De Backer, G., De Henauw, S., Huybrechts, I., Kornitzer, K., Leveque, A., Moreau, M., \& Van Oyen, H. 2005. The Belgian food consumption survey: aims, design and methods. Archives of Public Health, 63(1), 1-16.

EFSA. 2009. Technical report of EFSA prepared by Data Collection and Exposure Unit (DATEX) on "Monitoring of furan in food". The EFSA Scientific Report. 304:1-23.

Feinberg, M., Bertail, P., Tressou, J., \& Verger, P. 2006. Analyse des risques alimentaires. Paris: Lavoisier.

Fromberg, A., Fagt, S., \& Granby, K. 2009. Furan in heat processed food products including home cooked food products and ready-to-eat products. In: Report of the EFSA CFP/EFSA/DATEX/2007/03 The National Food Institute, the Technical University of Denmark. Available at URL address: http://www.efsa.europa.eu/fr/scdocs/doc/1e.pdf.

Hamberger, C., Kellert, M., Schauer, U. M., Dekant, W., \& Mally, A. 2010. Hepatobiliary Toxicity of Furan: Identification of Furan Metabolites in Bile of Male F344/N Rats. Drug Metabolism and Disposition, 38(10), 1698-1706. 
393 Hasnip, S., Crews, C., \& Castle, L. 2006. Some factors affecting the formation of furan in heated foods. Food Additives \& Contaminants: Part A, 23(3), 219-227.

395

396

397

398

399

400

401

402

403

404

405

406

407

408

409

410

411

412

413

414

415

416

417

418

419

420

421

422

423

424

425

426

Heppner, C. W., \& Schlatter, J. R. 2007. Data requirements for risk assessment of furan in food. Food Additives \& Contaminants: Part A, 24(S 1), 114-121.

Hickling, K.C., Hitchcock, J.M., Chipman, J.K., Hammond, T.G., Evans, J.G. 2010a. Induction and Progression of cholangiofibrosis in rat liver injured by oral administration of furan. Toxicol Pathol, 38(2), 213-229.

Hickling, K.C., Hitchcock, J.M., Oreffo, V., Mally, A., Hammond, T.G., Evans, J.G. 2010b. Evidence of oxidative stress and associated DNA damage, increased proliferative drive and altered gene expression in rat liver produced by cholangiocarcinogenic agent furan. Toxicol Pathol, 38(2), 230-243.

Kedderis, G. L., Carfagna, M. A., Held, S. D., Batra, R., Murphy, J. E., \& Gargas, M. L. 1993. Kinetic-analysis of furan biotransformation by F344 rats in-vivo and in-vitro. Toxicology and Applied Pharmacology, 123(2), 274-282.

Kim, T.-K., Lee, Y.-K., Kim, S., Park, Y. S., \& Lee, K.-G. 2009. Furan in Commercially Processed Foods: Four-Year Field Monitoring and Risk Assessment Study in Korea. Journal of Toxicology and Environmental Health, Part A: Current Issues, 72(21), 1304 $-1310$.

Kim, T.-K., Lee, Y.-K., Park, Y. S., \& Lee, K.-G. 2009. Effect of cooking or handling conditions on the furan levels of processed foods. Food Additives \& Contaminants: Part A, 26(6), 767-776.

Liu, Y. T., \& Tsai, S. W. 2010. Assessment of dietary furan exposures from heat processed foods in Taiwan. Chemosphere, 79(1), 54-59.

Maga, J. A. 1979. Furans in foods. CRC Critical Review in Food Science and Nutrition, 11(4), 355-400.

Moser, G.J., Foley, J., Burnett, M, Goldsworthy, T.L., Maronpot, R. 2009. Furan-induced dose-response relationships for liver cytotoxicity, cell proliferation, and tumorigenicity (furan-induced liver tumorigenicity). Experimental and Toxicologic Pathology, 61(2), 101-111.

NAS. 2000. Spacecraft Maximum Allowable Concentrations for Selected Airborne Contaminants. 4(B14):307-329. Available at the URL address: http://fermat.nap.edu/books/0309067952/html/307.html.

NTP. 1993. Toxicology and carcinogenesis studies of furan (CAS No. 110-00-9) in F344/N rats and $\mathrm{B} 6 \mathrm{C} 3 \mathrm{Fl}$ mice (gavage studies). NTP Technical Report No. 402., U.S. 
427

428

429

430

431

432

433

434

435

436

437

438

439

440

441

442

443

444

445

446

447

448

449

450

451

452

453

454

455

456

457

458

459

460

Department of Health and Human Services, Public Health Service, National Institutes of Health, Research Triangle Park, NC. Available at the URL address: http://ntp.niehs.nih.gov/ntp/htdocs/LT_rpts/tr402.pdf.

Peterson, L. A., Naruko, K. C., \& Predecki, D. P. 2000. A Reactive Metabolite of Furan, cis2-Butene-1,4-dial, Is Mutagenic in the Ames Assay. Chemical Research in Toxicology, 13(7), 531-534.

Peterson, L. A., Cummings, M. E., Vu, C. C., \& Matter, B. A. 2005. Glutathione trapping to measure microsomal oxidation of furan to cis-2-butene-1,4-dial. Drug Metabolism and Disposition, 33(10), 1453-1458.

Peterson, L. A., Cummings, M. E., Chan, J. Y., Vu, C. C., \& Matter, B. A. 2006. Identification of a cis-2-Butene-1,4-dial-derived Glutathione Conjugate in the Urine of Furan-Treated Rats. Chemical Research in Toxicology, 19(9), 1138-1141.

Reinhard, H., Sager, F., Zimmermann, H., \& Zoller, O. 2004. Furan in foods on the Swiss Market - Method and Results. Mitteilungen aus Lebensmitteluntersuchung und Hygiene, 95, 532-536.

Renwick, A. G., Barlow, S. M., Hertz-Picciotto, I., Boobis, A. R., Dybing, E., Edler, L., Eisenbrand, G., Greig, J. B., Kleiner, J., Lambe, J., Muller, D. J. G., Smith, M. R., Tritscher, A., Tuijtelaars, S., van den Brandt, P. A., Walker, R., \& Kroes, R. 2003. Risk characterisation of chemicals in food and diet. Food and Chemical Toxicology, 41(9), 1211-1271.

Roberts, D. P. T., Crews, C., Grundy, H., Mills, C., \& Matthews, W. 2008. Effect of consumer cooking on furan in convenience foods. Food Additives \& Contaminants: Part A, 25(1), 25-31.

Scholl, G., Scippo, M.-L., De Pauw, E., Eppe, G., Saegerman, C. 2011. First estimation of the furan contamination through the Belgian food chain. Food Additives \& Contaminants: Part B, Accepted.

Scholl, G., Scippo, M.-L., Focant, J.-F., De Pauw, E., Eppe, G. 2009. Validation of a subroom temperature ID-SPME-GC-MS method for the analysis of furan if food. In: Book of abstracts, $4^{\text {th }}$ International Symposium on Recent Advances in Food Analysis. p. 407.

Stadler, R. H., \& Anklam, E. 2007. Update on the progress in acrylamide and furan research. Food Additives \& Contaminants: Part A, 24(S 1), 1-2.

US-F.D.A. 2004. Furan in Food, Thermal treatment; Request for Data and Information. In: United States - Food and Drug Administration. 
461 Williams, G.M., Arisseto, A.P., Baines, J., DiNovi, M., Feeley, M., Schlatter, J., Slob, W., 462 Toledo, M.C.F., Vavasour, E. 2011. Safety Evaluation of certain contaminants in food. 463 Furan. WHO food additives series: 63, FAO JECFA monographs 8, 487-603. 464 Available the URL address: 465 http://whqlibdoc.who.int/publications/2011/9789241660631_eng.pdf.

466 Wegener, J.-W., \& Lopez-Sanchez, P. 2010. Furan levels in fruit and vegetables juices, 467 nutrition drinks and bakery products. Analytica Chimica Acta, 672(1-2, Sp. Iss. SI), $468 \quad 55-60$.

469 WHO. 2003. Instructions for electronic submission of data on chemical contaminants in food 470 and the diet. Global Environment Monitoring System - Food Contamination 471 Monitoring and Assessment Programme (GEMS/Food). Available at the URL address: 472 http://www.who.int/foodsafety/publications/chem/en/gemsmanual.pdf.

473 WHO. 2009. Environmental Health Criteria 240: Principles and methods for the risk 474 assessment of chemicals in food. Chapter 6: Dietary exposure assessment of chemicals 475 in food. International Program on Chemical Safety (IPCS). Geneva: WHO Press. 476 Available the URL address: 477 http://whqlibdoc.who.int/ehc/WHO_EHC_240_9_eng_Chapter6.pdf. 


\section{Table and figure caption}

\section{Table I.}

List of the distributions used for the probabilistic risk assessment (only distributions for samples >LOQ and for 'consuming' people are presented) according to the @ Risk software notations.

485

486

487

488

489

490

491

492

493

494

495

496

497

498

499

Table II.

Deterministic EDI $\left(\mathrm{ng} *\left(\mathrm{~kg}_{\text {b.w. }} * \text { day }\right)^{-1}\right)$ for several contamination approaches.

\section{Table III.}

Probabilistic EDI $\left(\mathrm{ng} *\left(\mathrm{~kg}_{\text {b.w. }} * \text { day }\right)^{-1}\right)$ for several contamination approaches.

\section{Figure 1.}

Title: Deterministic EDI for the average population, including the contribution of the most relevant food groups.

\section{Figure 2.}

Title: (A): Distribution of the EDI across the population in the deterministic approach, and (C) Same as A but for the probabilistic 500 approach; $(\mathbf{C})$ : Distribution of the MoE across the population in the deterministic approach; 501 (D): Same as $\mathrm{C}$ for the probabilistic approach.

502

503

504

505

Figure 3.

506 507

Title: Influence of decreasing or increasing the daily coffee consumption by one cup on the EDI of the average population, including the contribution of the most relevant food groups. 
Table I. List of the distributions used for the probabilistic risk assessment (only distributions for samples >LOQ and for 'consuming' people are presented) according to the @ Risk software notations.

\begin{tabular}{|c|c|c|}
\hline Food group & @ Risk Contamination distribution & @Risk Consumption distribution \\
\hline Vegetables & $\begin{array}{l}\text { RiskBetaGeneral }(0.21931 ; 0.22834 ; 0.8 ; 30.6 \\
\text { 8) }\end{array}$ & $\begin{array}{l}\text { RiskPearson5(7.9716;1688.8;RiskShift(- } \\
75.196) \text { ) }\end{array}$ \\
\hline Fruits & $\begin{array}{l}\text { RiskPearson5(0.87353;1.1588;RiskShift }(0 . \\
13385))\end{array}$ & $\begin{array}{l}\text { RiskPearson5(6.8822;1997.4;RiskShift(- } \\
\text { 120.74)) }\end{array}$ \\
\hline $\begin{array}{l}\text { Milk and } \\
\text { Milky } \\
\text { beverages }\end{array}$ & $\begin{array}{l}\text { RiskLognorm(3.3751;2.9041;RiskShift(- } \\
0.5535))\end{array}$ & RiskLoglogistic(-54.643;288.93;5.0313) \\
\hline $\begin{array}{l}\text { Dessert } \\
\text { cream }\end{array}$ & RiskNormal(7.358;7.209) & RiskLoglogistic(-16.106;148.06;3.764) \\
\hline $\begin{array}{l}\text { Pasta, Rice, } \\
\text { Other Grain }\end{array}$ & RiskExtvalue(22.516;27.748) & $\begin{array}{l}\text { RiskLognorm(203.84;132.09;RiskShift(- } \\
\text { 27.127)) }\end{array}$ \\
\hline $\begin{array}{l}\text { Breakfast } \\
\text { Cereals }\end{array}$ & $\begin{array}{l}\text { RiskLognorm(33.178;32.292;RiskShift(- } \\
1.3011) \text { ) }\end{array}$ & $\begin{array}{l}\text { RiskPearson5(8.3866;564.71;RiskShift(- } \\
\text { 23.071)) }\end{array}$ \\
\hline Biscuits & RiskNormal $(25.721 ; 19.913)$ & $\begin{array}{l}\text { RiskInvgauss(49.638;67.916; RiskShift(- } \\
4.3678) \text { ) }\end{array}$ \\
\hline Raw Meat & $\begin{array}{l}\text { RiskBetaGeneral }(0.27138 ; 0.35639 ; 0.32 ; 66 . \\
93)\end{array}$ & RiskInvgauss(101.66;226;RiskShift(-11.664)) \\
\hline $\begin{array}{l}\text { Processed } \\
\text { meat }\end{array}$ & $\begin{array}{l}\text { RiskInvgauss(4.0861;0.7775;RiskShift }(0.17 \\
294))\end{array}$ & $\begin{array}{l}\text { RiskInvgauss(67.906;106.439;RiskShift(- } \\
4.1765))\end{array}$ \\
\hline Fish & RiskExpon(23.148;RiskShift(-0.79903)) & RiskBetaGeneral( $1.4836 ; 5.9922 ; 1.6382 ; 526.32)$ \\
\hline $\begin{array}{l}\text { Chocolate, } \\
\text { Candy Bars, } \\
\text { Paste, etc. }\end{array}$ & RiskUniform(-0.33556;8.9656) & RiskPearson5(3.793;147.04;RiskShift(-11.33)) \\
\hline $\begin{array}{l}\text { Confectioner } \\
\text { and Non- } \\
\text { Chocolate }\end{array}$ & $\begin{array}{l}\text { RiskBetaGeneral }(0.18312 ; 0.21331 ; 0.72 ; 8.7 \\
\text { 9) }\end{array}$ & $\begin{array}{l}\text { RiskInvgauss(37.276;33.348;RiskShift(- } \\
\text { 2.6119)) }\end{array}$ \\
\hline Cakes & $\begin{array}{l}\text { RiskPearson5(1.2746;5.7504;RiskShift(1.4 } \\
743))\end{array}$ & $\begin{array}{l}\text { RiskInvgauss(48.025;79.124;RiskShift(- } \\
\text { 3.4931)) }\end{array}$ \\
\hline $\begin{array}{l}\text { Fruit And } \\
\text { Vegetable } \\
\text { Juices }\end{array}$ & RiskLoglogistic(-0.6429;2.0314;5.2505) & RiskLoglogistic(-72.436;278.71;3.2801) \\
\hline Soft drinks & RiskTriang(-0.018347;0.95;1.6178) & $\begin{array}{l}\text { RiskInvgauss(635.46;1093.9; RiskShift(- } \\
\text { 57.616)) }\end{array}$ \\
\hline Coffee & $\begin{array}{l}\text { RiskBetaGeneral }(0.4086 ; 0.47225 ; 1.13 ; 106 . \\
\text { 23) }\end{array}$ & $\begin{array}{l}\text { RiskPearson5(4.9426;2648.5;RiskShift(- } \\
\text { 191.14)) }\end{array}$ \\
\hline Tea & $\begin{array}{l}\text { RiskBetaGeneral }(0.29271 ; 0.27597 ; 0.37 ; 2.8 \\
7)\end{array}$ & RiskLognorm(338.95;321.83;RiskShift(39.603) \\
\hline Herbal Tea & $\begin{array}{l}\text { RiskBetaGeneral }(0.18842 ; 0.20477 ; 0.22 ; 3.6 \\
\text { 8) }\end{array}$ & $\begin{array}{l}\text { RiskPearson5(4.2366;1363.5;RiskShift(- } \\
80.915))\end{array}$ \\
\hline Wine & RiskLoglogistic(0.19764;0.30883;2.0584) & $\begin{array}{l}\text { RiskLognorm(287.29;189.16;RiskShift(- } \\
26.305))\end{array}$ \\
\hline Beer, Cider & $\begin{array}{l}\text { RiskInvgauss(3.9075;19.794;RiskShift(- } \\
1.2641))\end{array}$ & RiskPearson5(3.0816;1457;RiskShift(-129.34)) \\
\hline $\begin{array}{l}\text { Tomato } \\
\text { Sauces }\end{array}$ & RiskLogistic(11.2955;2.9182) & $\begin{array}{l}\text { RiskInvgauss(73.018;30.148;RiskShift(- } \\
0.36396))\end{array}$ \\
\hline Soups & $\begin{array}{l}\text { RiskInvgauss(25.542;10.767;RiskShift(- } \\
0.5567))\end{array}$ & RiskExtvalue(241.22;109.2) \\
\hline $\begin{array}{l}\text { Miscellaneou } \\
\mathrm{S}\end{array}$ & $\begin{array}{l}\text { RiskPearson5(5.8123;82.114;RiskShift(- } \\
7.3599) \text { ) }\end{array}$ & RiskLoglogistic(2.7612;71.036;2.4976) \\
\hline $\begin{array}{l}\text { Soya } \\
\text { Products }\end{array}$ & RiskExtvalue(1.3338;1.1449) & RiskInvgauss(135.6;45.027;RiskShift(-4.31)) \\
\hline
\end{tabular}


1

2

3

4

5

6

7

8

9

10

11

12

13

14

15

16

17

18

19

20

21

22

23

24

25

26

27

28

29

30

31

32

33

34

35

36

37

38

39

40

41

42

43

44

45

46

47

48

49

50

51

52

53

54

55

56

57

58

59

60

Table II. Deterministic EDI $\left(\mathrm{ng} *\left(\mathrm{~kg}_{\mathrm{b} . w .} * \text { day }\right)^{-1}\right)$ for several contamination approaches.

\begin{tabular}{|l|l|l|l|}
\hline \multicolumn{5}{|l}{} \\
\hline First Quartile & Lower Bound & Middle Bound & Upper Bound \\
\hline Median & 191 & 192 & 193 \\
\hline Mean & 329 & 330 & 331 \\
\hline Third Quartile & 379 & 380 & 381 \\
\hline
\end{tabular}


Table III. Probabilistic EDI $\left(\mathrm{ng} *\left(\mathrm{~kg}_{\mathrm{b} . w .} * \text { day }\right)^{-1}\right)$ for several contamination approaches.

\begin{tabular}{|l|c|c|c|c|}
\hline & Lower Bound & Middle Bound & Upper Bound & Uniform \\
\hline Mode & 25 & 23 & 27 & 23 \\
\hline First Quartile & 80 & 80 & 82 & 81 \\
\hline Median & 211 & 212 & 213 & 212 \\
\hline Mean & 494 & 494 & 488 & 494 \\
\hline Third Quartile & 492 & 493 & 493 & 493 \\
\hline Proportion of results $\mathbf{P ~ R f D ~}_{\text {ora }}(\%)$ & 8.1 & 8.1 & 8.1 & 8.1 \\
\hline
\end{tabular}




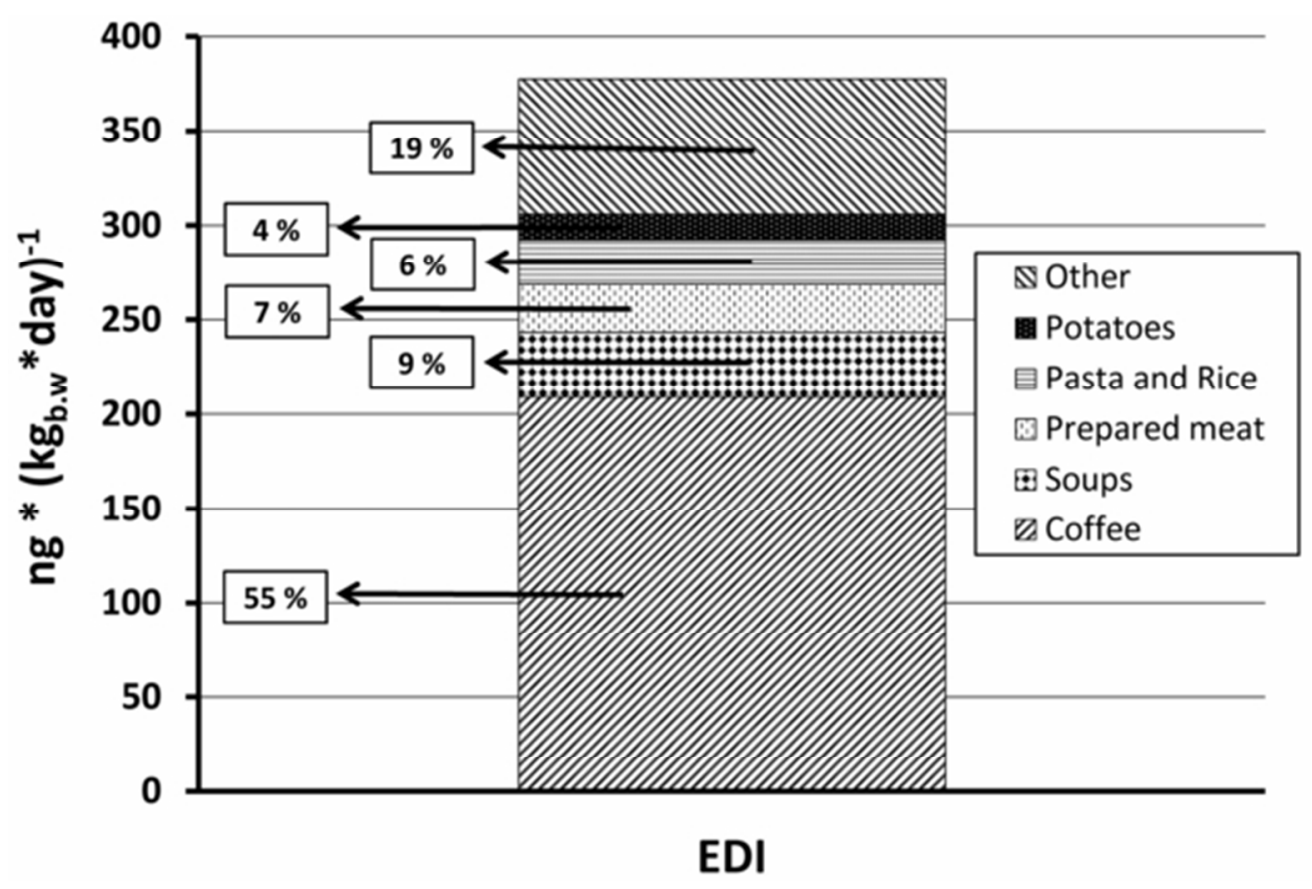

$53 \times 35 \mathrm{~mm}(300 \times 300$ DPI $)$

http://mc.manuscriptcentral.com/tfac Email: fac@tandf.co.uk 

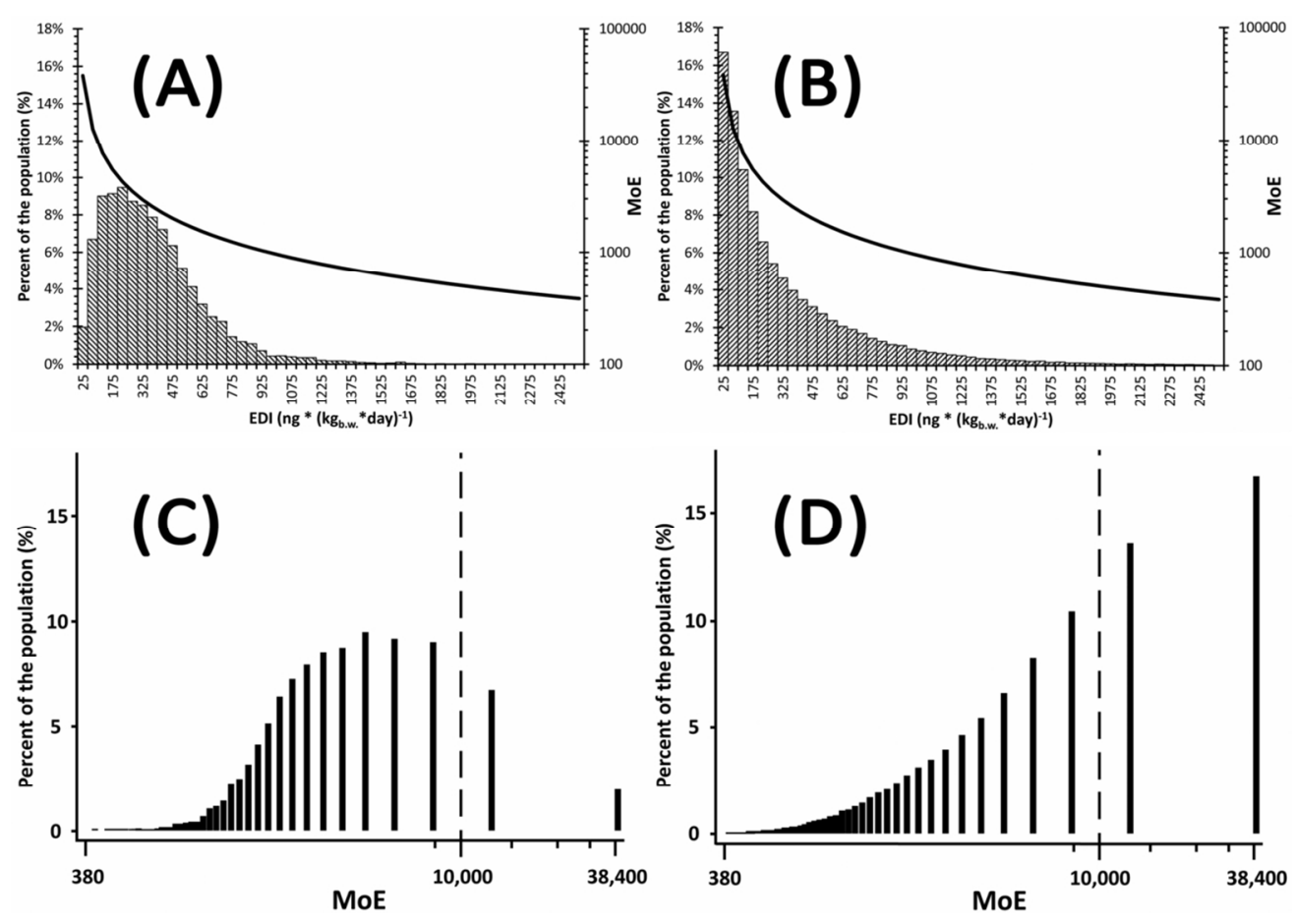

$112 \times 78 \mathrm{~mm}(300 \times 300$ DPI $)$ 


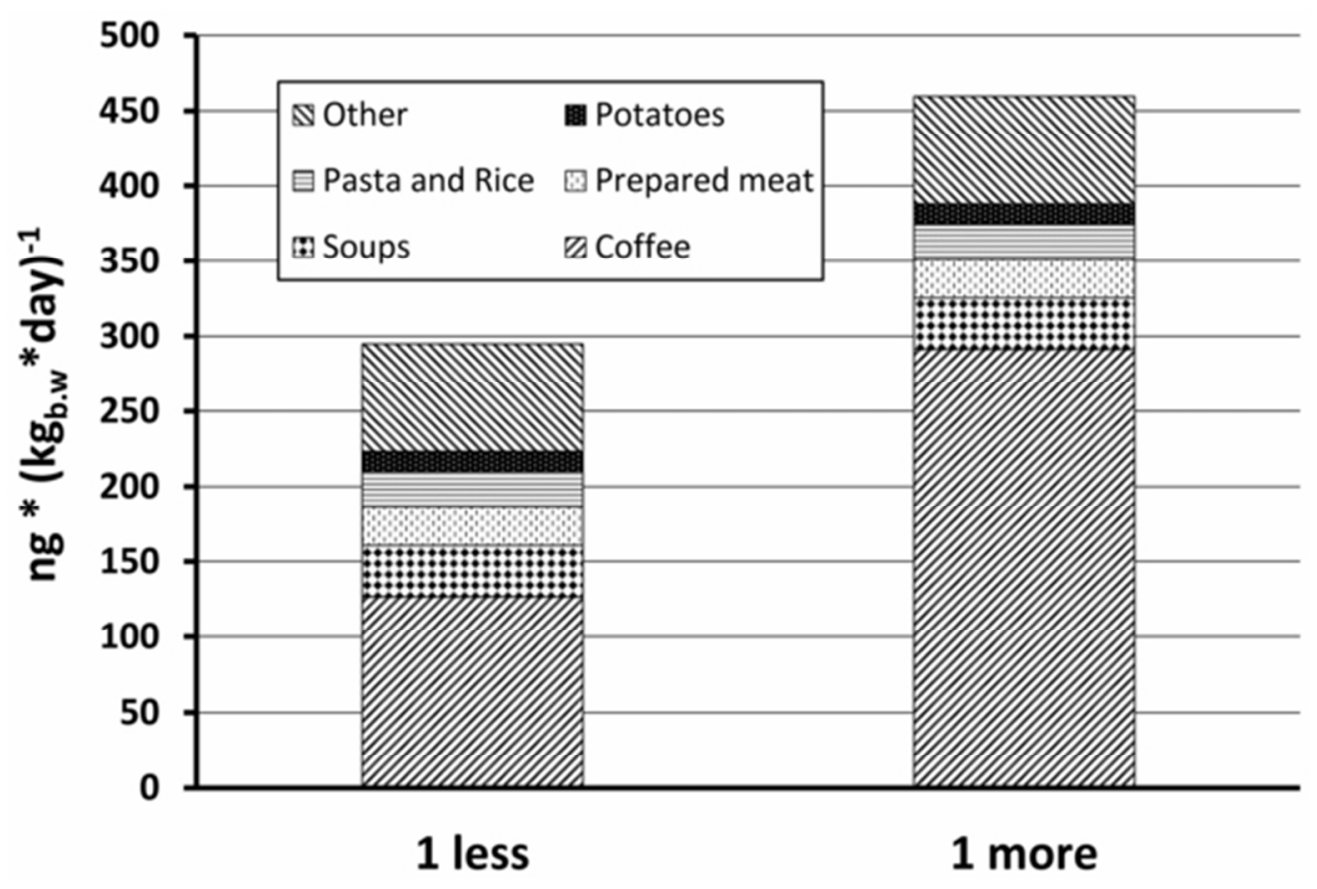

$53 \times 35 \mathrm{~mm}(300 \times 300$ DPI $)$ 